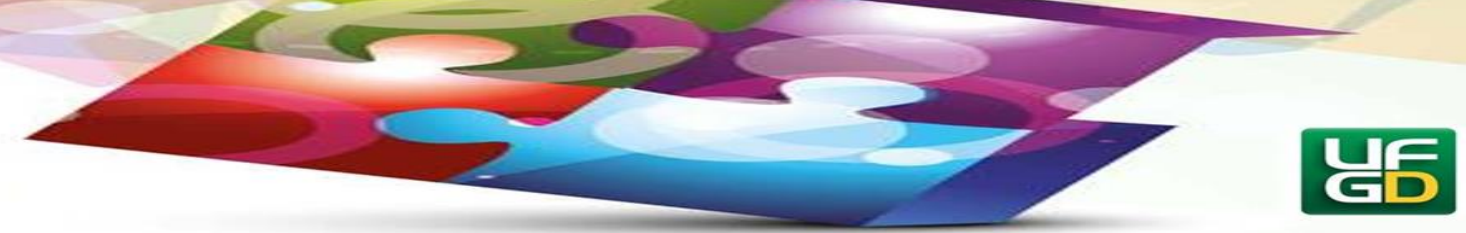

\title{
ANÁliSE dE LIVRO DIDÁTICO E A PRÁTICA PEDAGÓgICA DO PROFESSOR QUE ENSINA MATEMÁTICA
}

\section{TEXTBOOK ANALYSIS AND PEDAGOGICAL PRACTICE OF THE TEACHER WHO TEACHES MATHEMATICS}

Resumo: neste artigo, evidenciamos o recorte de um projeto de pesquisa que teve por objetivo o estudo das contribuições da análise de livro didático para a prática pedagógica do professor que ensina Matemática. Em sua prática pedagógica, dentre outras ações, cabe ao professor conceber um tratamento adequado aos conteúdos matemáticos para que esses possam se tornar potencialmente significativos aos alunos. Porém, quais elementos teóricos estão à disposição do professor para selecionar e desenvolver o rol de conteúdos matemáticos? De que modo essa ação contribui para a sua prática pedagógica? Essas questões nos motivaram a analisar, pela perspectiva da Teoria Antropológica do Didático, como três livros didáticos abordam o conceito de Função para alunos do $9^{\circ}$ ano do Ensino Fundamental e que elementos promovem a (re)construção da prática pedagógica do professor que ensina Matemática.

Palavra-chave: Prática Pedagógica. Análise de Livro Didático. Educação Matemática. Currículo de Matemática

\begin{abstract}
: in this article, we show the cut of a search project that had for goal, the study of contribuitions at the textbook analysis for the pedagogical practice of the teacher wo teaches Mathematics. In its pedagogical practice, among other actions, it is up to the teacher to grant a suitable treatment to the mathematics contentes for them to become potentially significant to the students. Although, which theoretical elements are at disposal to the teacher to select and develop the list of mathematics contentes? In which way this action contributes for his pedagógica practice? Those questions, motivated us to analyze, by the Anthropological Teaching Theory perspective, so three textbooks approach the concepts of Function for students from $9^{\text {th }}$ grade and which elements promote the (re)construction of pedagogical practice of the teacher who teaches mathematics.
\end{abstract}

Keywords: Pedagogical Practice. Textbook Analysis. Mathematics Education. Mathematics Curriculum.

\section{Considerações iniciais}

\footnotetext{
1 Doutor em Educação Matemática Pontífica Universidade Católica de São Paulo (PUC-SP). Professor da Universidade Federal de Ouro Preto (UFOP). E-mail: januario@ufop.edu.br.
} 


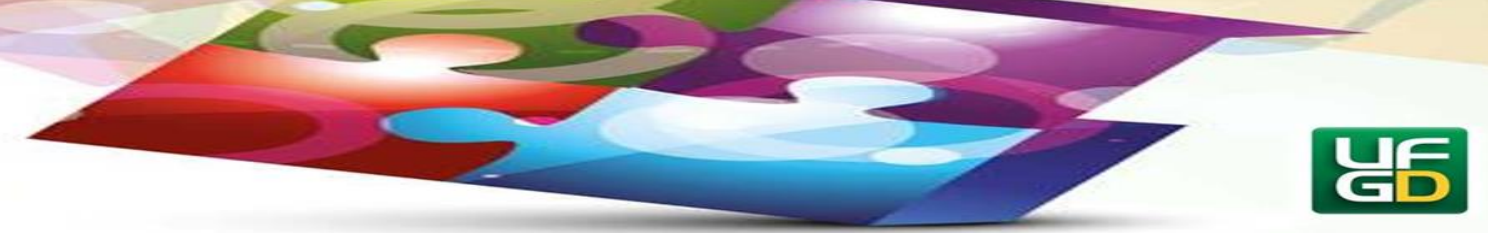

Os professores estão envolvidos em diversas atividades no ambiente escolar, as quais objetivam promover, em sala de aula, as condições favoráveis para que estudantes compreendam os conceitos e construam a aprendizagem matemática. Para tanto, faz-se necessário que o professor articule algumas ações: organizar e desenvolver o currículo que atenda às necessidades de aprendizagem da turma; escolher o material didático que melhor corresponda a essas necessidades; elaborar instrumentos avaliativos; desenvolver estratégias metodológicas apropriadas; e dar tratamento aos conteúdos de ensino. Essa última ação constitui-se de uma tarefa imprescindível, pois os conteúdos formam o saber a ser aprendido (PAIS, 2008).

Rocha e Ponte (2006) citam as recomendações dos documentos do National Council of Teachers of Mathematics (NCTM) e da Associação dos Professores de Matemática (APM) de Portugal em relação à importância das atividades a serem trabalhadas em Matemática. Esses documentos expõem que o trabalho desenvolvido em sala de aula pode se dar a partir de atividades apropriadas que encaminhem os estudantes a exploração, descobertas e reflexão, o que é possível "propiciar aos alunos experiências matemáticas significativas, que promovem o seu 'saber matemático', de modo que 'saber matemática' corresponde a 'fazer matemática'” (ROCHA e PONTE, 2006, p. 30).

Para possibilitar a compreensão dos conceitos a partir de um conjunto de experiências matemáticas potencialmente significativas e promover o saber matemático, o professor recorre aos livros didáticos para selecionar e organizar os conteúdos. Essa prática deve ser realizada a partir de critérios de escolha, análise crítica dos conteúdos e situações-problema a seres abordadas ao mediar/promover situações de aprendizagem.

Nesse sentido, o professor pode avaliar qual é o tratamento dado aos conteúdos e se esse tratamento possibilita um trabalho a partir da investigação e das descobertas matemáticas. A análise de conteúdos de livros didáticos constitui-se de estudo, investigação, avaliação, teste e desenvolvimento do que é proposto nas unidades didáticas presentes nas obras. Todavia, esta análise deve se dar com intencionalidade, portanto, requer uma reflexão sobre os saberes que serão mobilizados e construídos pelos alunos e de que modo a abordagem dada pelos elaboradores dos materiais podem efetivamente contribuir nesse processo. A prática de analisar os conteúdos permite ao professor de Matemática a possibilidade de identificar os tipos de situações-problema que favoreçam um ambiente em que os estudantes possam trabalhar 


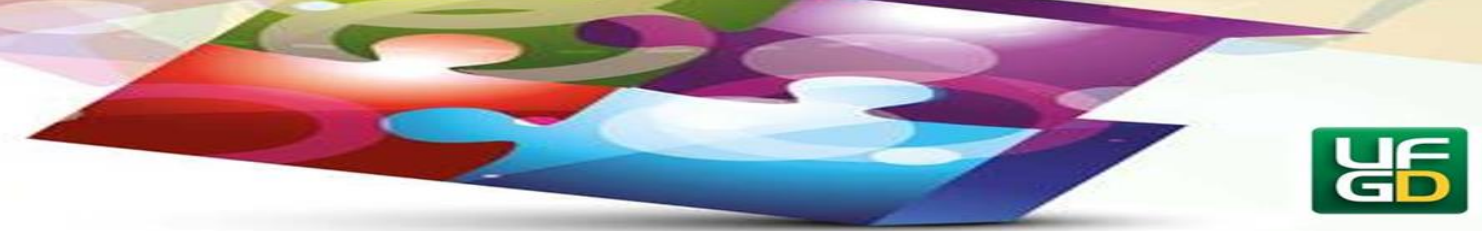

matematicamente e, como consequência, construir sentidos e significados dos conceitos abordados (JANUARIO, 2010).

Nesse cenário, é relevante que a escola conceba seu projeto educacional objetivando uma formação crítica e transformadora. Formar estudantes críticos, que reflitam sobre os problemas da sociedade e que tenham condições para nela intervir, transformando sua realidade, requer posturas pedagógicas diferenciadas. Desse modo, conforme a postura do professor e suas concepções filosófico-pedagógicas em conceber suas aulas, a análise de conteúdo possibilita a escolha pelo livro didático que venha ao encontro do currículo a ser desenvolvido e que, a partir da abordagem dada pelos autores, promova/potencializa nos estudantes as competências e habilidades matemáticas esperadas pelos documentos oficiais que orientam o currículo escolar.

A análise de conteúdos de livros didáticos de Matemática pode ser um norte que direciona o professor a realizar suas atividades e ensinar/mediar processos de aprendizagem matemática que desenvolva no estudante o raciocínio crítico-reflexivo-transformador. Ao refletir sobre esse processo, algumas questões têm nos inquietado: Que elementos teóricos o professor dispõe para selecionar e desenvolver o rol de conteúdos matemáticos? De que modo essa ação contribui para a sua prática pedagógica?

Essas questões nos aproximaram do projeto de pesquisa que teve por objetivo identificar as contribuições da análise de livro didático para a prática pedagógica do professor que ensina Matemática.

\section{Sobre a prática pedagógica do professor}

Em Educação, especificamente em Educação Matemática, o termo prática pedagógica tem sido presente nas produções com foco nas questões relacionadas aos processos de ensino e de aprendizagem e, consequentemente, ao conjunto de atividades desenvolvidas pelo professor que ensina Matemática nos diferentes níveis e modalidades de ensino.

O vocábulo prática, conforme dicionários da língua portuguesa, refere-se a um determinado tipo de ação, o que viabiliza - ou não - a realização de atividades rotineiras, relacionadas às experiências, fruto do trabalho e dos fazeres cotidianos. O vocábulo pedagógica está relacionado ao conjunto de atividades compreendidas pela área do saber que trata da educação e da instrução escolar de crianças, adolescentes, jovens e adultos, portanto, a 


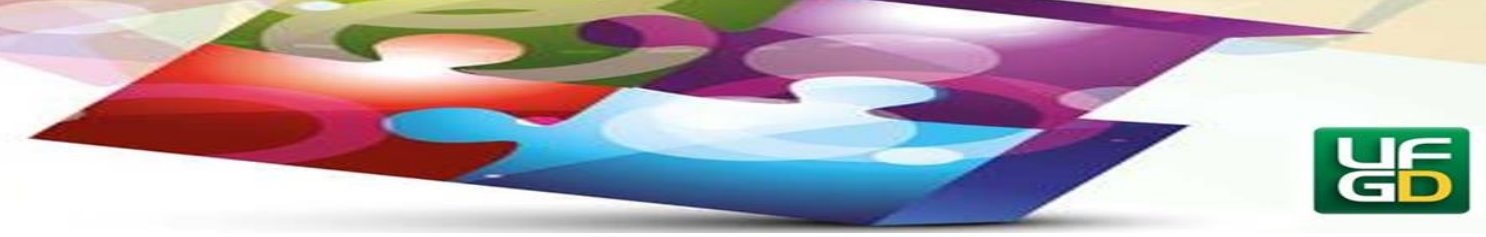

Pedagogia. Então, a prática pedagógica pode ser entendida enquanto um conjunto de ações e de atividades rotineiras do profissional da educação.

Os Parâmetros Curriculares Nacionais de Matemática para o Ensino Fundamental, PCN, (BRASIL, 1998) expõem a relevância da compreensão do conceito dessa prática desenvolvida por professores. Esses documentos esclarecem que, ao levar em conta o processo históricosocial de mudanças de ideias frente ao universo escolar, é possível identificar divergências no modo de se conceber as atividades do professor, mesmo porque, até então não se tinha clareza quanto à natureza destas atividades.

Conforme expõem os PCN, o tecnicismo educacional, estimulado pelo behaviorismo e demais teorias que focavam uma abordagem sistemática do ensino, marcaram a década de 1970 e determinaram "uma prática pedagógica altamente controlada e dirigida pelo professor, com atividades mecânicas inseridas numa proposta educacional rígida e passível de ser totalmente programada em detalhes" (BRASIL, 1998, p. 31).

Esse documento sugere que esse modo de conceber a prática pedagógica promoveu processos de ensino conteudistas e enrijecidos e processos de aprendizagem mecânicos e, possivelmente, fora do contexto histórico-social do aluno, implicando em resultados de aprendizagem sem relação com questões sociais ou temas de interesse dos alunos, baseada em práticas que pouco contribuíam para a construção de sentidos e significados dos conceitos abordados. Em oposição a esse modelo de prática, os PCN evidenciam que a prática pedagógica não pode ser resumida a um conjunto de ideias e/ou habilidades, pois se trata de um saber-fazer que está em constante atualização devido à heterogeneidade do público alvo a que se destina os processos de ensino e de aprendizagem.

Ao escrever sobre a prática do professor, Souza (2005) evidencia dois aspectos que a constituem: o social e a sala de aula. A prática pedagógica como parte de um processo que envolve a dimensão educativa na esfera da escola e fora dela é vista como o primeiro aspecto. Em relação à esfera escolar, as atividades dos professores referem-se às reuniões com os pais dos alunos e com a comunidade; à organização da semana de planejamento; à participação em de reuniões de estudo com os pares; à participação em conselhos de classe ou de escola. No que se refere à prática pedagógica fora do espaço escolar, são exemplos o engajamento nos movimentos sociais; adesão ao movimento de greves; participação em assembleias, passeatas ou reuniões de sindicatos. 


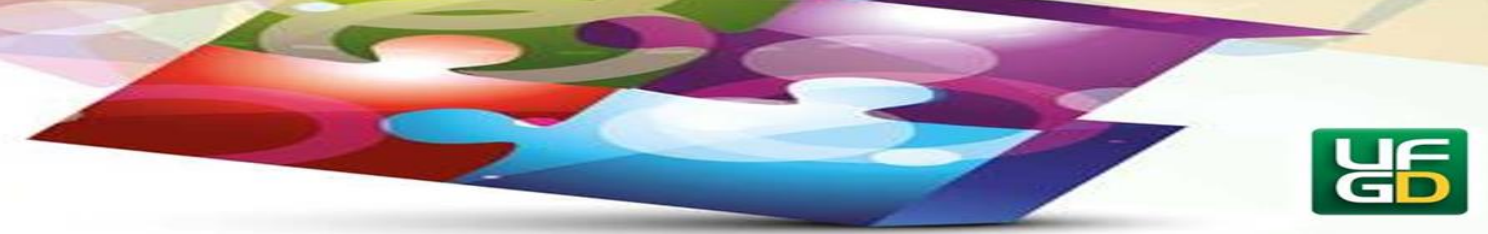

No entender de Souza (2005), a prática pedagógica, que é social, é produzida por esses movimentos, os quais têm como conteúdos centrais "a política, a estratégia de negociação, a organização, a definição de objetivos, a articulação com outras organizações sociais, desenvolvendo teias ou redes de informação e ação política" (p. 2).

Em relação ao segundo aspecto - relacionado à sala de aula - a prática pedagógica compreende o conjunto de ações desenvolvidas pelo docente, no cenário escolar, ao mediar/promover processos de aprendizagem e nesse cenário evidenciam-se suas múltiplas dimensões: "professor, aluno, metodologia, avaliação, relação professor e alunos, concepção de educação e de escola" (SOUZA, 2005, p. 3).

Em relação à prática social, Veiga (1992) argumenta que a prática pedagógica é orientada por "objetivos, finalidades e conhecimentos [...]. A prática pedagógica é uma dimensão da prática social que pressupõe a relação teoria-prática, e é essencialmente nosso dever, como educadores, a busca de condições necessárias à sua realização" (p. 16).

Entendemos, em ambos os aspectos destacados por Souza (2005), que a prática do professor reflete uma postura social e indicam dois tipos de práticas: a que envolve as dimensões sociais de um processo social e constitui a prática docente, que não relaciona-se diretamente com os processos de ensino e de aprendizagem, mas com um conjunto de ações fora do contexto de sala de aula; a que está estreitamente ligada às atividades do professor ao ensinar/mediar processos de aprendizagem e constitui a prática pedagógica, caracterizada pelas ações do professor frente a seleção, organização e o desenvolvimento de conteúdos curriculares conforme as necessidades de aprendizagem da classe; escolha pelo material didático que melhor atenda aos objetivos do ensino; elaboração de instrumentos avaliativos; estratégias metodológicas desenvolvidas; e tratamento a ser dado aos conteúdos de ensino. Portanto, todo o conjunto de trabalho realizado em sala de aula ou em função do desenvolvimento curricular.

Por ser uma dimensão da prática docente, deste modo, social, a prática pedagógica do professor que ensina Matemática deve estabelecer uma concepção de ensino e de aprendizagem em que os objetivos estejam em harmonia com uma formação transformadora, preparando os estudantes para posicionarem-se de forma crítica e reflexiva frente às situações políticaeconômico-social.

Assim, ensinar/mediar processos de aprendizagem matemática significa possibilitar estratégias para a formação do ser humano pautadas na construção da ética e de valores. Para 


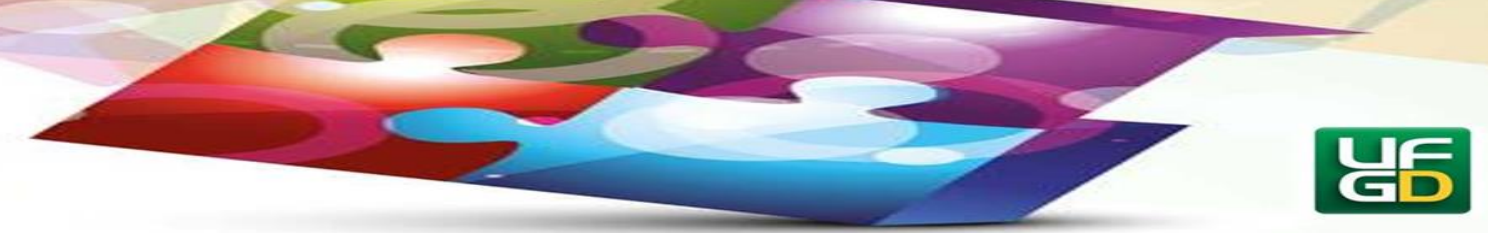

tanto, o professor precisa constituir sua prática pedagógica que venha ao encontro desse perfil de educação.

Embora constituir-se professor possa se dar em momentos que antecedem o curso universitário, é na formação inicial que a prática pedagógica passa pelo processo de concepção. D’Ambrosio (2005), ao escrever sobre esse processo, expõe os desafios emergentes desta prática sob a ótica do professor formador, ressaltando a necessidade de “[...] explorar e investigar atividades que levem o futuro professor a se dispor a analisar o trabalho dos alunos e, ao mesmo tempo, estimulá-lo a desenvolver seu conhecimento matemático de maneira mais complexa" (p. 23). Assim, a formação inicial torna-se o cenário propício para que o futuro professor possa constituir sua prática pedagógica, a partir das experiências vivenciadas na licenciatura, de forma marcante, influente e exemplar.

No entanto, a prática pedagógica pode ser remodelada, reconstituída, ressignificada inúmeras vezes, de acordo com o interesse do professor e a necessidade do público a que se destina. É possível identificar na apresentação dos PCN (BRASIL, 1998) que esse documento objetiva auxiliar o professor acerca da reflexão frente a sua prática pedagógica. Ao considerarmos que a Matemática, por muitos anos, foi ensinada de forma conteudista, de currículo enrijecido, pensamos que (re)pensar a prática pedagógica em Matemática torna-se fundamental para que se promova os avanços científicos e tecnológicos que desencadeiem uma educação de qualidade.

Assim, a escolha do livro didático que melhor promova situações investigadoras e problematizadoras de modo a despertar a curiosidade e o interesse dos estudantes pode se constituir uma ação que promova o professor a (re)pensar sua prática pedagógica. A escolha do livro didático e a reflexão crítica sobre o modo que os autores desses materiais abordam os conteúdos se constituem atividades que requer rigor do professor, pois é a partir da seleção de conteúdos que o docente fará uma transposição do currículo prescrito, portanto oficial, para o currículo praticado, aquele efetivamente desenvolvido.

Todavia, o aspecto social da prática pedagógica não reflete apenas na preocupação de cumprir ou não o currículo, mas, sobretudo, na qualidade dos conteúdos a serem trabalhados. Por isso, pensamos que a partir de critérios definidos, os professores podem realizar análise sobre os conteúdos apresentados nos livros didáticos. 


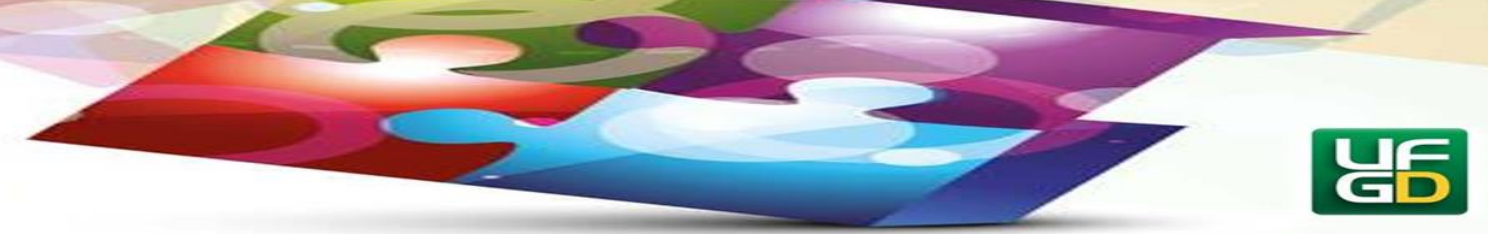

A pesquisa que desenvolvemos (JANUARIO, 2010) procurou investigar quais são as contribuições da análise de livros didáticos para a prática pedagógica do professor que ensina Matemática. Neste artigo, procuramos apresentar um recorte desse trabalho, objetivando responder que elementos são evidenciados para que o professor possa repensar, remodelar, reconstituir sua prática pedagógica.

\section{Contextualizando a pesquisa}

Em nossa trajetória como formadores e professores que ensinam Matemática, temos identificado que a prática do professor tem se constituído em desenvolver ações que promovam processos de ensino e aprendizagem significativos para os estudantes, aos pais, ao próprio professor e à comunidade escolar. Possivelmente por isso, algumas investigações na linha de pesquisa em Formação de Professores que ensinam Matemática (PAIVA e NACARATO, 2006; LOPES e CURI, 2008; FIORENTINI e CRISTÓVÃO, 2010) têm focado seus objetivos em estudar as ações do professor frente ao rol de atividades didático-pedagógicas no que diz respeito aos processos de ensino e de aprendizagem e nos saberes que esses profissionais mobilizam para mediar/promover esses processos.

Assim, ao estudar a prática do professor que ensina Matemática, busca-se identificar quais são as ações desenvolvidas por esse profissional ao mediar/promover processos de aprendizagem matemática e de que modo essas ações (re)constroem a prática.

Nessa perspectiva, ao analisar conteúdos matemáticos abordados por autores de livros didáticos, o professor torna-se um investigador do material a ser utilizado por ele e por seus alunos. Nesse entender, a pesquisa procurou identificar quais as contribuições da organização praxeológica ao abordarem a introdução ao conceito de Função, presente nos livros didáticos de Matemática para o $9^{\circ}$ ano do Ensino Fundamental, à prática do professor de Matemática (JANUARIO, 2010).

Optamos pelo tema Função por tratar-se de um conceito amplamente estudado no Ensino Médio e trabalhado a partir de suas variações e aplicações nas múltiplas disciplinas, por exemplo, Matemática, Física, Química, Biologia e Geografia. Desse modo, embora seja um conceito matemático, a aplicação de Função é um tratamento multidisciplinar que se inicia no 


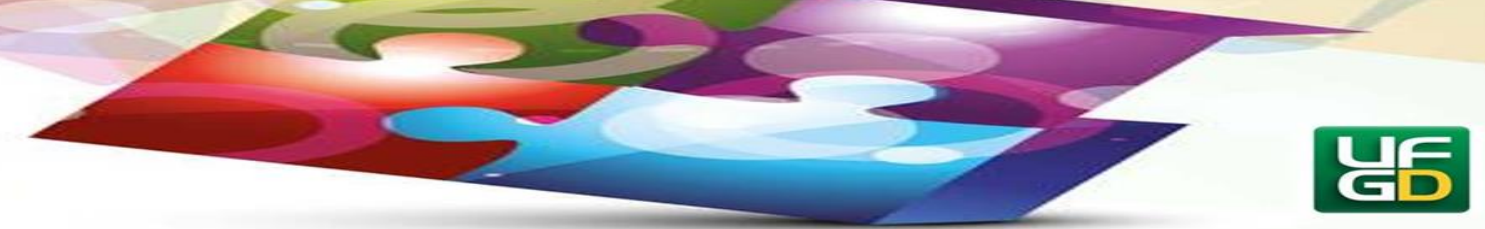

Ensino Fundamental, no $9^{\circ}$ ano. Inicialmente identificamos que algumas pesquisas já tinham focado suas problemáticas sobre o tema Função.

O trabalho desenvolvido por Oliveira (1997) constatou que há dificuldades no campo conceitual de Função nos diferentes níveis de ensino, o que a levou a trabalhar com estudantes do primeiro ano do curso de Engenharia por meio de sequências didáticas objetivando a conceituação de Função, propiciando para esses estudantes a construção de significados frente a tal conceito.

A investigação realizada por Rossini (2006) consistiu em um trabalho colaborativo com professores para identificar as concepções e as dificuldades desses docentes frente ao conceito de Função. $\mathrm{O}$ estudo foi desenvolvido a partir da construção de uma sequência didática que tratava do ensino desse conteúdo para turmas de $9^{\circ}$ ano do Ensino Fundamental, procurando identificar quais organizações matemáticas são mobilizadas pelos professores para tal construção. A pesquisa revelou que, conforme constroem as organizações didáticas, eles reconstroem seus saberes sobre Função.

Maia (2007) realizou um estudo sobre o ensino de Funções Quadráticas e do uso de softwares no processo de aprendizagem do conceito de Função. Após realizar análise em alguns livros didáticos, o trabalho de campo foi constituído por grupos de alunos do $9^{\circ}$ ano que realizaram sequência didática solicitando o tratamento gráfico e algébrico de Funções Quadráticas com o auxílio do Winplot, papel e lápis. A pesquisadora expõe que houve um avanço por parte desses alunos frente à construção do conceito desse tipo de Função.

A escolha por conteúdos que propiciem um ambiente favorável para que o estudante possa investigar, tentar, errar, construir, averiguar e socializar o que está trabalhando é um fator que promoverá a aprendizagem significativa. Desse modo, a postura do professor não está presente apenas nas ações de sala de aula, mas no processo de organização e desenvolvimento dos conteúdos a serem trabalhados pelos alunos.

Em relação aos conteúdos, percebemos, em nossa prática enquanto professores que ensinam/mediam processos de aprendizagem matemática, que os estudantes apresentam dificuldades ao trabalhar com o tema Função. Desse modo, a análise de conteúdo possivelmente permite ao professor mobilizar saberes, mudar posturas, (re)constituir sua prática pedagógica e promover novas propostas de aprendizagem. 


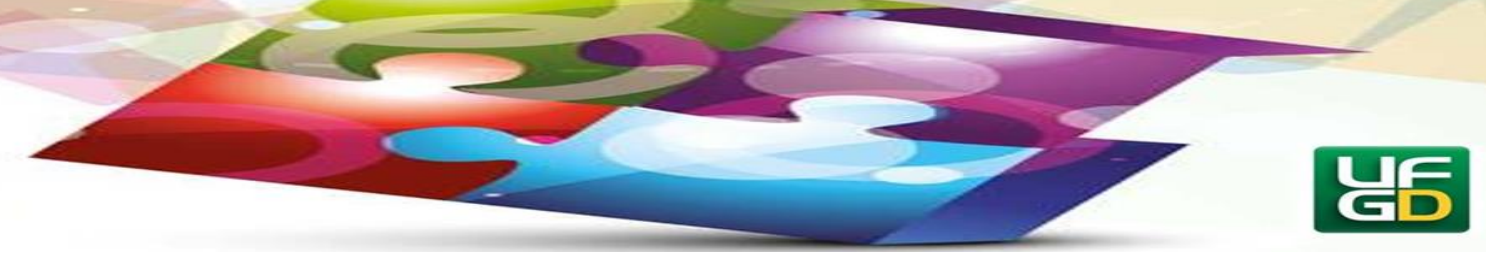

Para que pudéssemos chegar ao objetivo da investigação, escolhemos três livros didáticos do $9^{\circ}$ ano visando identificar de que modo os autores introduzem o conceito de Função. Para Sacristán (2000), o livro didático, enquanto um dos intervenientes do currículo, influencia de forma acentuada a prática do professor. No entender desse autor, essas obras são, na maioria das vezes, as principais fontes para elaboração das aulas, a partir do que os autores desses materiais propõem. Por outro lado, o professor toma conhecimento do currículo prescrito a partir do elenco de conteúdos abordados pelos autores dos livros didáticos.

Para a escolha, nos pautamos nos critérios: (i) um dos livros apresentasse proposta inovadora; (ii) os outros dois livros apresentassem uma proposta mais "tradicional"; e (iii) os três livros tivessem sido usados por nós, na condição de estudantes e/ou professores.

A partir dos critérios de escolha, selecionamos três livros didáticos, para identificarmos, por meio da análise, a organização praxeológica presente na introdução ao conceito de Função. Os livros adotados, conforme ilustras as Figuras 1,2 e 3, foram: (i) A Conquista da Matemática, de autoria de Jose Ruy Giovanni, Benedito Castrucci e José Ruy Giovanni Junior, faz parte de uma coleção da editora F.T.D. composta por livros para todos os anos do ensino fundamental, publicado em 2002; (ii) Matemática, de autoria de Luiz Marcio Imenes e de Marcelo Cestari Terra Lellis, publicado pela editora Scipione em 1997 e constou do catálogo do Programa Nacional do Livro Didático (PNLD) de 2001; e (iii) Projeto Araribá: Matemática, de autoria coletiva, publicado pela editora Moderna, em 2006 e fez parte do catálogo do PNLD de 2008.

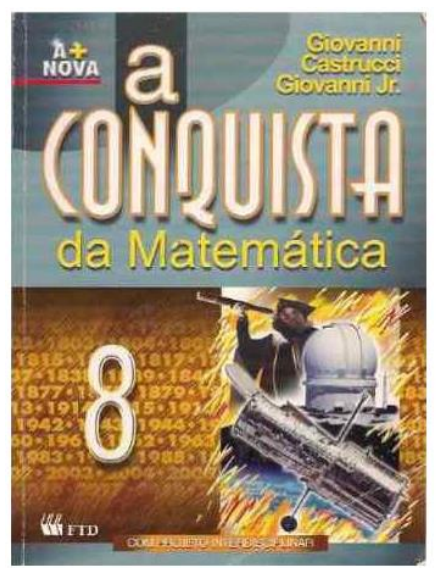

Figura 1: Capa do livro A conquista da Matemática

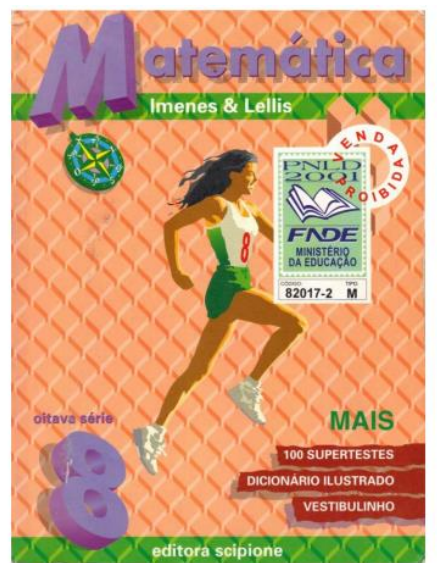

Figura 2: Capa do livro Matemática

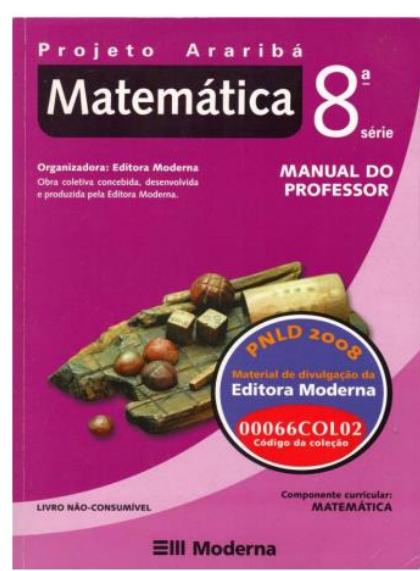

Figura 3: Capa do livro Projeto Araribá Matemática 


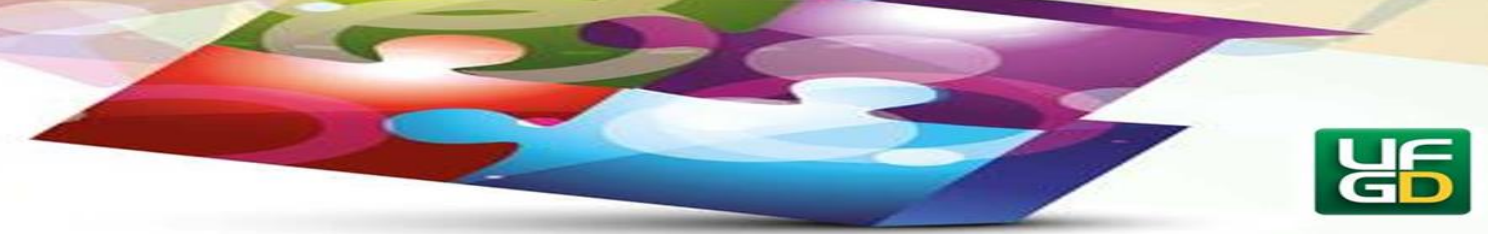

A pesquisa consistiu de uma investigação na perspectiva da pesquisa qualitativa conforme concebem Lüdke e André (1986). Esse tipo de pesquisa nos auxiliou no processo de estudo por propiciar o encontro de respostas muito particulares, em que há um nível de realidade e fidedignidade a partir da análise e de interpretação a luz de significados, motivos, aspirações, crenças, valores e atitudes, que não podem ser quantificados, mas que correspondem a um espaço mais profundo das relações, dos processos e dos fenômenos que não são reduzidos à operacionalização de variáveis, conforme entendem esses autores.

Para a análise crítica das estratégias utilizadas pelos autores, nos pautamos na Organização Praxeológica presente na Teoria Antropológica do Didático (CHEVALLARD, 1999), referente às Tarefas, Técnicas, Tecnologias e Teorias.

$\mathrm{Na}$ análise dos tipos de tarefas propostas nos livros escolhidos, observamos:

- se apresentavam abordagem histórica do conceito de Função;

- se possibilitavam favorecer a fase adidática, conforme a Teoria das Situações Didática (BROUSSEAU, 2008); e

- se apresentavam diferentes tipos de registros e suas devidas conversões, presentes na teoria de Registro de Representação Semióticas (DUVAL, 2003).

Não explicitaremos, aqui, os referenciais teóricos que sustentaram a análise feita dos conteúdos propostos pelos autores dos três livros didáticos. É possível encontrá-los no relatório final da Pesquisa desenvolvida (JANUARIO, 2010).

A partir do referencial teórico e da metodologia, analisamos as situações-problema propostas pelos autores dos três livros ao abordarem a introdução ao conceito de Função. Posteriormente, elaboramos um quadro com os tipos de tarefas apresentadas nos três livros e o número de vezes que elas ocorreram nos exemplos e nos exercícios propostos.

Para facilitar a citação das obras, chamamos de A, o livro A Conquista da Matemática; de B, o livro Matemática; e de C o livro Projeto Araribá: Matemática. Em relação ao conceito de Função, os autores dos livros A e C propuseram situações que visavam à abordagem pela relação entre duas grandezas e relação entre dois conjuntos; os autores do livro B abordaram por meio da relação entre duas grandezas enfatizando a interdependência dessas grandezas e as variações (direta ou inversamente proporcionais). 


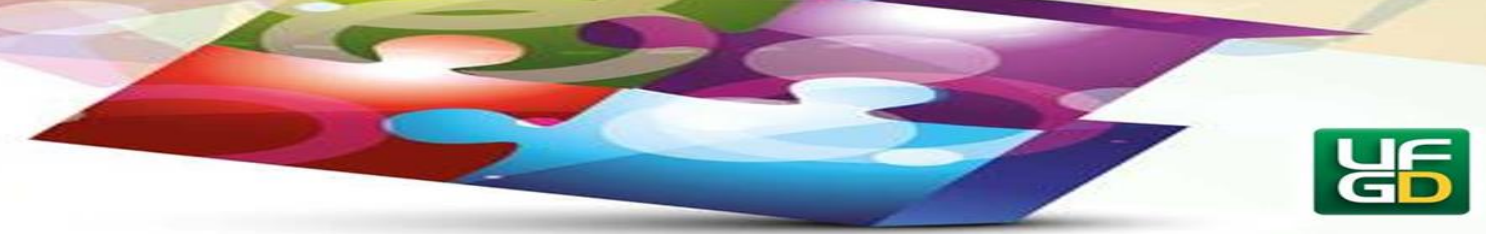

Sobre a Teoria das Situações Didáticas (BROUSSEAU, 2008), as situações apresentadas nos livros $\mathrm{A}$ e $\mathrm{C}$ não favoreciam a fase adidática, enquanto o as situações apresentadas no livro B, favoreciam.

Quanto à abordagem histórica, apenas os livros B e C apresentaram situações que faziam referência à história da Matemática: os autores do livro B fizeram três referências e os autores do livro C, uma referência.

Em relação ao Registro de Representação (DUVAL, 2003):

- quanto ao registro: nos três livros analisados, os autores propuseram situações com tabelas, leis, diagramas e gráficos, prevalecendo o registro algébrico; no livro A, não houve a abordagem do registro gráfico;

- quanto à conversão: as situações propostas pelos autores do livro A compreenderam as conversões linguagem natural $\rightarrow$ lei, tabela $\rightarrow$ diagrama e lei $\rightarrow$ diagrama; as situações do livro B possibilitaram as conversões linguagem natural $\rightarrow$ lei, linguagem natural $\rightarrow$ tabela, tabela $\rightarrow$ lei, lei $\rightarrow$ tabela e lei $\rightarrow$ tabela $\rightarrow$ gráfico; e as situações do livro C compreenderam as conversões linguagem natural $\rightarrow$ lei, tabela $\rightarrow$ lei, lei $\rightarrow$ tabela gráfico.

Quanto à Organização Praxeológica (CHEVALLARD, 1999):

- tipos de Tarefa: as situações propostas no livro A apresentaram 23 tipos de tarefas nos exemplos e 39 nos exercícios propostos; em relação ao livro B, foram 10 tipos nos exemplos e 38 nos exercícios propostos; quanto ao livro $\mathrm{C}$, as situações propostas apresentaram 24 tipos de tarefas nos exemplos e 46 nos exercícios propostos;

- os tipos de Tarefas que apareceram com maior frequência nos três livros foram: (a) Determinar a lei de formação de uma Função a partir de um texto; (b) Identificar os diagramas que representam Função; (c) Completar Tabela; (d) Descobrir a fórmula a partir de uma tabela; (e) Determinar a imagem de um número conhecida a lei de formação da Função; e (f) Determinar o valor de x dada a sua imagem.

\section{Contribuições da análise de livro didático à prática do professor de Matemática}

Critérios permeiam a prática pedagógica do professor que ensina/media processos de aprendizagem matemática. Para realizar atividades rotineiras de sala de aula, esse profissional 


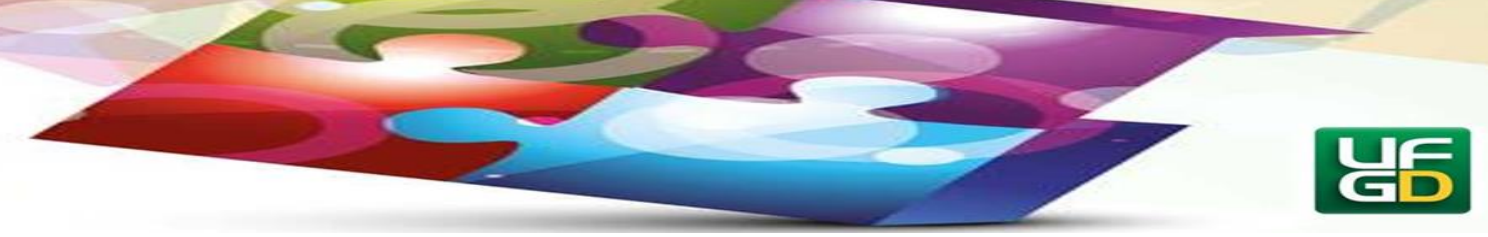

se utiliza de parâmetros para escolher os materiais que utilizará com seus alunos; para selecionar, elaborar ou desenvolver situações problematizadoras e de investigação; e para criar um ambiente favorável à construção dos significados e à apropriação dos conceitos matemáticos.

Mas qual a origem dos critérios? Possivelmente no decorrer de sua carreira no magistério, o professor desenvolva suas atividades com o olhar crítico, questionando-se o porquê de utilizar determinado material ou propor determinada atividade, vislumbrando as competências e habilidades a serem desenvolvidas pelos estudantes. Essa postura, então, subsidia a prática do professor dando-lhe elementos para estabelecer e nortear suas escolhas.

Se concebermos o saber-fazer docente sustentado por teorias - as quais o professor teve contato na formação inicial ou em que o contato se deu em cursos de formação continuada -, os critérios emergem de teorias que norteiam as ações do professor no cenário escolar. Os critérios se constituem, então, de elementos que direcionarão o olhar investigativo do professor para as atividades de seu trabalho pedagógico. Desse modo, ao selecionar livros didáticos que apresentem a abordagem dos conteúdos mais adequada para que promova, nos alunos, a construção da aprendizagem, é fundamental que o professor tenha critérios frente às situaçõesproblema propostas pelos autores desses materiais.

Nessa perspectiva, a pesquisa evidenciou que a análise de livro didático apresenta elementos para que o professor estabeleça um olhar avaliativo frente à abordagem dada aos conteúdos e atividades apresentadas pelos autores desses materiais. Porém, a análise deve ser concebida a partir de parâmetros apresentados por teorizações ou elaborados a partir delas.

A análise do tratamento dado pelos autores dos livros didáticos à introdução ao conceito de Função, a partir da Organização Praxeológica (CHEVALLARD, 1999), propiciou identificar nas atividades propostas os tipos de tarefas, as possibilidades de técnicas mobilizadas pelos estudantes e o discurso teórico-tecnológico. Em relação à Teoria das Situações Didáticas (BROUSSEAU, 2008), foi possível identificar quais atividades propiciavam um ambiente para que os estudantes pudessem manipular seus saberes, criar hipóteses, socializar suas dúvidas com os colegas e desenvolver as situações de modo a construir os significados matemáticos.

Quanto ao Registro de Representação Semiótica (DUVAL, 2003), essa teoria possibilitou identificar nos conteúdos se haviam ou não diferentes quadros, registros e mudanças de quadros, permitindo ao professor selecionar, descartar ou complementar as 


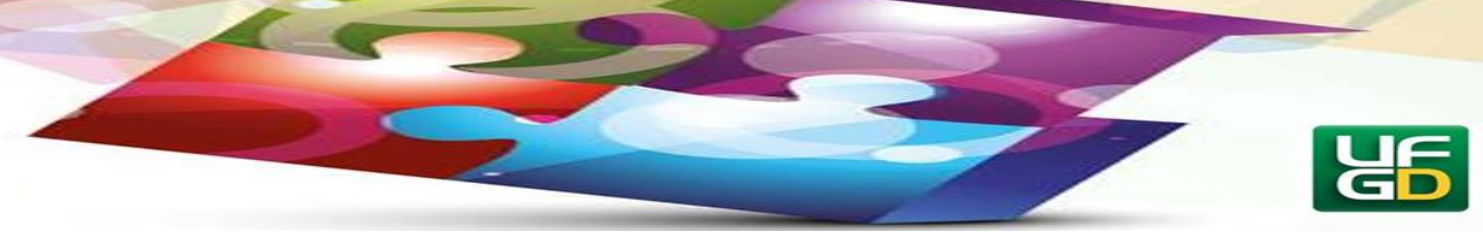

atividades que contribuíssem para que os estudantes trabalhassem os conceitos a partir de diferentes pontos de vista no contexto matemático.

A análise de livro didático contribui para que o professor possa vislumbrar sua postura em sala de aula, ao conceber ações que promovam um ambiente favorável à aprendizagem do aluno. Desse modo, analisar livro didático traz elementos para que o professor possa (re)pensar, (re)modelar, (re)constituir sua prática pedagógica, uma vez que o conjunto de ações relacionadas aos processos de ensino e de aprendizagem passa a ser concebido a partir de uma postura crítica e reflexiva do professor que ensina/media processos de aprendizagem matemática.

Identificar as situações propostas em livros didáticos que melhor atendam as expectativas e objetivos de aprendizagem, possibilita ao professor refletir sobre o aluno que ele está formando e vislumbrar o modo que esse estudante desenvolve seu raciocínio para apropriar-se dos saberes matemáticos. A atividade de analisar livro didático permite ao professor fazer intervenções no processo de aprendizagem, mediando as relações entre o estudante e o saber matemático que está sendo construído. Desse modo, tal atividade auxilia o professor a selecionar, organizar e desenvolver o currículo apresentado e, ao identificar os saberes mobilizados pelos estudantes, permite que o professor desenvolva uma avaliação no processo em que ocorre a aprendizagem, diferente de modelos avaliativos realizados ao final de um determinado período letivo e que objetiva apenas verificar se houve ou não a apropriação dos conceitos trabalhados.

Portanto, realizar análise de livros didáticos apresenta elementos para que o professor possa refletir sobre sua prática pedagógica e nela intervir, redesenhando suas ações frente aos processos de ensino e de aprendizagem dos saberes matemáticos, vislumbrando potencialidades desses processos na construção dos significados e na apropriação dos conceitos que estão sendo trabalhados.

\section{Considerações finais}

Ao retomarmos as questões que direcionaram este recorte - Que elementos teóricos o professor dispõe para selecionar e desenvolver o rol de conteúdos matemáticos? De que modo essa ação contribui para a sua prática pedagógica? - entendemos ser relevante que o 


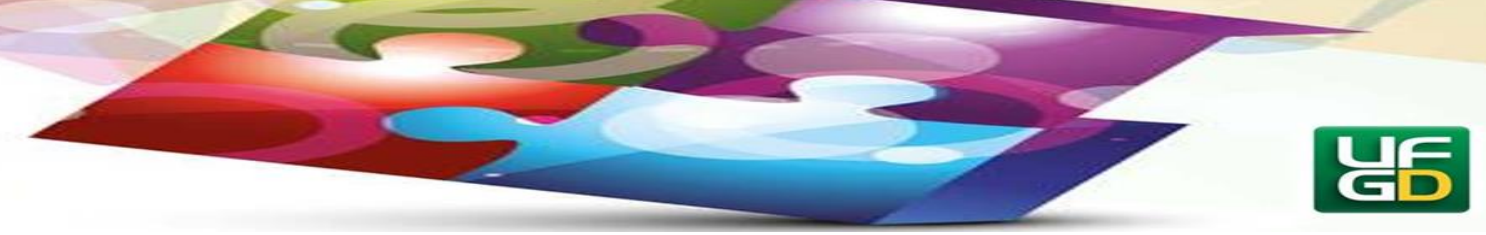

profissional em educação entenda e compreenda os conceitos teóricos que estão relacionados aos processos de ensino e de aprendizagem.

Dentre as diferentes atividades que constituem a prática pedagógica, o professor que ensina/media processos de aprendizagem matemática também seleciona, desenvolve, adapta os conteúdos prescritos nos documentos oficiais, que geralmente são parâmetros, orientações ou propostas curriculares. Esses documentos expressam um conjunto de concepções teóricas, textualizadas pelos autores e por aqueles que idealizam tais materiais.

Nessa perspectiva, os elementos teóricos que o professor dispõe para selecionar e desenvolver o rol de conteúdos matemáticos são aqueles devidamente explicitados nesses documentos. Outros elementos são apresentados ao longo de sua trajetória docente, desde a formação inicial, inclusive as reflexões e discussões promovidas por periódicos da área ou materiais institucionais das secretarias de educação.

Entendemos, assim, que o contato com as teorizações e as contribuições de pesquisas em Educação Matemática pode constituir-se um fator relevante para a mudança de posturas na prática pedagógica do professor, dando possibilidade para que este encontre e dê sentido ao ensino de Matemática e contextualize o seu saber. Concebemos contextualizar não apenas no sentido de se fazer relações com as atividades cotidianas dos estudantes, mas, também, buscar significar o saber matemático por meio da contextualização interna à Matemática.

Desse modo, a prática pedagógica do professor poderá ser concebida de forma interdisciplinar, não apenas no sentido de buscar referenciais em diversas áreas do conhecimento, mas realizar suas atividades por meio de situações-problema que visem conceber o saber a partir de diversas perspectivas dos conceitos e teorias.

A análise de livro didático compreende uma ação que contribui para a prática pedagógica do professor que ensina/media processos de aprendizagem matemática, pois desperta nesse profissional um olhar crítico e investigativo no processo de seleção de material didático, situações-problema e elaboração de atividades; fomenta o despertar de interesse pelas questões didático-pedagógicas à luz dessas teorias, não de forma teórica, mas procurando colocá-las em prática nas atividades enquanto docente.

Tal prática de analisar conteúdos abordados em livros didáticos propicia elementos que promovem o desejo e a prática de explorar o repertório de conteúdos, materiais e atividades, instigando a prática da análise prévia do conjunto de situações-problema sugeridas para a sala 


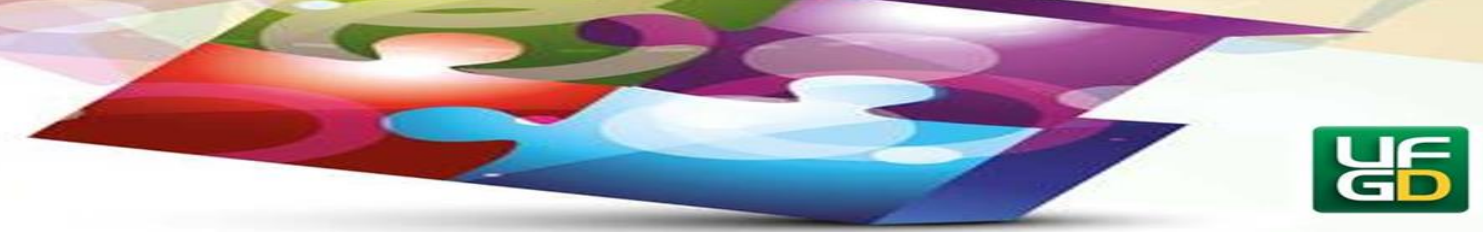

de aula, antes de propor aos estudantes. Também, promove a reflexão em relação ao currículo de Matemática para os diferentes níveis e modalidades de ensino.

Pensar o currículo de Matemática é vislumbrar os elementos que o compõem e de que forma ele se manifesta no cenário educacional: prescrito, apresentado, em ação, moldado pelo docente, praticado e avaliado, conforme esclarece Sacristán (2000). Portanto, a análise de livro didático coloca o professor diante de possibilidades de intervenção, a partir da prática pedagógica, na transposição do currículo apresentado para o currículo praticado.

Mas o que é pensar em possibilidades na prática pedagógica? É vislumbrar um trabalho a partir de certezas, de objetivos alcançados. É realizar um trabalho permitindo que o estudante acesse os saberes matemáticos, apropriando-se dos conceitos e construindo aprendizagens significativas.

\section{Referências}

BRASIL. Secretaria de Educação Básica. Parâmetros Curriculares Nacionais: terceiro e quarto ciclos do Ensino Fundamental: Matemática. MEC/SEB, 1998.

BROUSSEAU, G. Introdução ao estudo das Situações Didáticas: conteúdos e métodos de ensino. Tradução de Camila Bogéa. São Paulo: Ática, 2008.

CHEVALLARD, Y. L'analyse des pratiques enseignantes en théorie anthropologique du didactique. In: Recherches en Didactique des Mathématiques, vol. 19, n. 2, p. 221-266, 1999.

D’AMBROSIO, B. Cultura e metodologia na formação de professores. In: FIORENTINI, D.; NACARATO, A. M. (Org.). Cultura, formação e desenvolvimento profissional de professores que ensinam matemática. São Paulo: Musa, 2005, p. 20-32.

DUVAL, R. Registros de Representação Semióticas e funcionamento cognitivo da compreensão da Matemática. In: MACHADO, S. D. A. (Org.). Aprendizagem em matemática: Registros de Representação Semiótica. Campinas: Papirus, 2003, p. 11-33.

FIORENTINI, D.; CRISTOVÃO, E. M. (Org.). Histórias e Investigações delem Aulas de Matemática. 2. ed. Campinas: Alínea, 2010.

GIOVANNI, J. R.; CASTRUCCI, B.; GIOVANNI JUNIOR, J. R. A conquista da Matemática: 8a série. São Paulo: FTD, 2002.

IMENES, L. M. P.; LELLIS, M. C. T. Matemática: 8ª série. São Paulo: Scipione, 2004. 


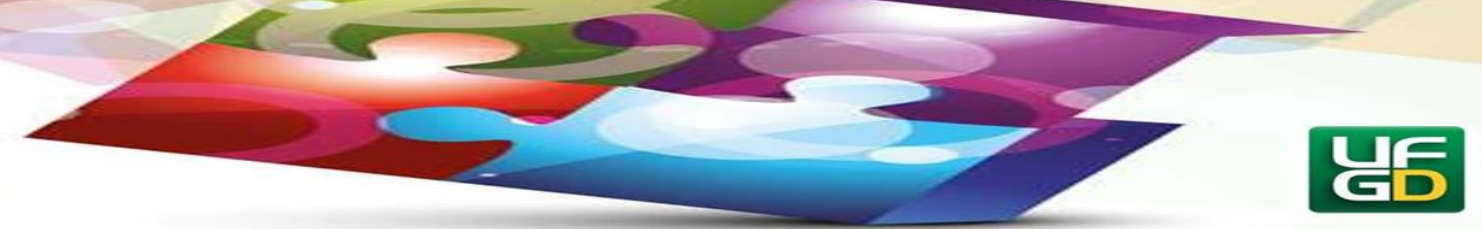

JANUARIO, G. Análise de conteúdo de livros didáticos: contribuições à prática do professor de Matemática. 2010. 72f. Monografia (Especialização em Formação de Professores).

Instituto Federal de Educação, Ciência e Tecnologia de São Paulo. São Paulo: IFSP, 2010.

LOPES, C. E.; CURI, E. (Org.). Pesquisas em Educação Matemática: um encontro entre a teoria e a prática. São Carlos: Pedro e João Editores, 2008.

LÜDKE, M.; ANDRÉ, M. E. D. A. Pesquisa em Educação: abordagens qualitativas. São Paulo: Editora Pedagógica e Universitária, 1986.

MAIA, D. Função Quadrática: Um estudo didático de uma abordagem computacional. 2007. 141f. Dissertação (Mestrado em Educação Matemática) - Faculdade de Ciências Exatas e Tecnologias, Pontifícia Universidade Católica de São Paulo. São Paulo: PUC, 2007.

OLIVEIRA, N. Conceito de Função: uma abordagem do processo ensino-aprendizagem. 1997, 174f. Dissertação (Mestrado em Ensino de Matemática) - Faculdade de Ciências Exatas e Tecnologias, Pontifícia Universidade Católica de São Paulo. São Paulo: PUC, 1997.

PAIS, L. C. Transposição Didática. In: MACHADO, S. D. A. (Org.). Educação Matemática: uma (nova) introdução. 3. ed. (revisada). São Paulo: EDUC, 2008, p. 11-48.

PAIVA, M. A. V.; NACARATO, A. M. (Org.). Formação do Professor que Ensina Matemática: Perspectivas e Pesquisas. Belo Horizonte: Autêntica, 2006.

Projeto Araribá: Matemática 8a série (obra coletiva). São Paulo: Moderna, 2006.

ROCHA, A.; PONTE, J. P. Aprender matemática investigando. In: Zetetikè. Campinas. v. 14. n. 26, p. 30-54, 2006.

ROSSINI, R. Saberes docentes sobre o tema Função: uma investigação das praxeologias. 2006, 384f. Tese (Doutorado em Educação Matemática) - Faculdade de Ciências Exatas e Tecnologias, Pontifícia Universidade Católica de São Paulo. São Paulo: PUC, 2006.

SACRISTÁN, J. G. O currículo: uma reflexão sobre a prática. 3. ed. Tradução: Ernani F. da Fonseca Rosa. Porto Alegre: Artmed, 2000.

SOUZA, M. A. Prática Pedagógica: conceito, características e inquietações. In: IV Encontro Ibero-Americano de Coletivos Escolares e Redes de Professores que fazem Investigação na sua Escola. Lajeado. Anais do IV EIACERP. Lajeado: UNIVATES, 2005, p. 1-7.

VEIGA, I. P. A. A prática pedagógica do professor de Didática. 2. ed. Campinas: Papirus, 1992.

Enviado: 28/06/2018

Aceito: $22 / 09 / 2018$ 